\title{
Information systems supported organizational learning as a competitive advantage
}

\author{
Jose Manuel Arias, Julian Miguel Solana \\ Organization Engineering Group, Department of Organization Engineering, Business Administration and Statistics. \\ Technical University of Madrid (Spain) \\ jose.arias@,sloan.mit.edu,jimsa@,gio.etsit.upm.es
}

Received: September 2012

Accepted: March 2013

\section{A bstract:}

Purpose The purpose of this paper is to analyze the characteristics that make information systems useful in gathering and processing information with the aim of organizational learning and subsequent structural adaptation for better fitting to market requirements.

Design/methodalog/approadr Adaptation is a must when turning to foster the competitiveness and sustainability of the organization.

Findings: It is clear that information systems can really create a difference in the way an organization acquires information from its environment and from itself in order to achieve a high-quality decision taking process.

Research limitations/implications: Organizations have to look inside themselves in order to ensure the comprehension of their core competencies and the way they carry them out.

Practical implications: Organizational learning is one of the means employed by organizations to get adapted to their surrounding environment.

Social implications: Systems engineering techniques can be applied in order to leverage these core competencies and make organizations adaptable to the organizational environment requirements through the use of information systems. 
Originality/value To obtain competitive advantages in the market.

Keywords: competitive advantage, information systems, knowledge management, the learning organization

\section{Information systems}

Information systems (IS) are the set of people, materials and communication procedures organized in order to deliver information to who may need it in an adequate time and format. Presently, information systems are based on software platforms devoted to the acquisition, storage, processing and dissemination of information (Laudon \& Laudon, 2009); evidently the aforementioned software is installed in the corresponding computer hardware, which is interconnected by data networks.

A way of classifying information is according to a criterion based on its origin. Therefore, if it is usually gathered from an external environment, it will be environmental information; on the other hand, when it is obtained from the inside of the organization itself, it will be inside information.

The data corresponding to this information is stored within a software storage system like a disk drive. It can then be used to help the organization owning the corresponding information system make decisions, either by means of mathematical rules or by disseminating information that can be used by the individuals within the organization as a basis for their choosing.

Information systems are related to their environment in the sense that relevant information is taken from it, but also in that decision taking supported by them has an outcome that can modify this environment, which produces a feedback that allows checking the decision effectiveness. This relationship is depicted in Figure 1 below.

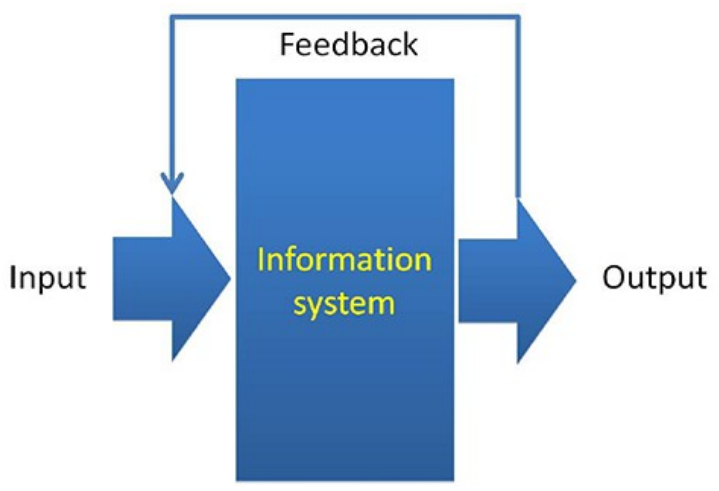

Figure 1. Information system within its environment

Presently, there are many kinds of information systems based on information technologies: Enterprise Resource Planning (ERP), Customer Relationship Management (CRM), Supply Chain 
Management (SCM), etc. On the one hand, ERP systems refer to the handling of information within a single organization.

On the other hand, CRM systems refer to the handling of information between a given organization and its customer organization. In this case, the input of the system would come from the organization itself or the customer organization, and the output of the system would go to the customer organization or the organization itself, respectively.

Finally, SCM systems refer to the handling of information between a given organization and its supplier organization. In this case, the input of the system would come from the organization itself or the supplier organization, and the output of the system would go to the supplier organization or the organization itself, respectively. ERP, CRM and SCM systems are depicted in Figure 2 below.

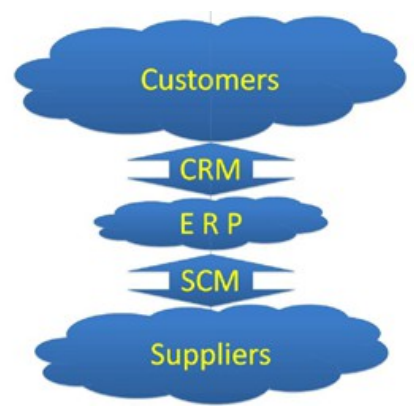

Figure 2. Relationship among CRM, ERP and SCM

Finally, SCM systems refer to the handling of information between a given organization and its supplier organization. In this case, the input of the system would come from the organization itself or the supplier organization, and the output of the system would go to the supplier organization or the organization itself, respectively. ERP, CRM and SCM systems are depicted in Figure 2 below.

It can also be noted that the CRM system depicted in Figure 2 is also a SCM system for the customer organization, and that the SCM system depicted in the same figure is also a CRM system for the supplier organization.

\section{Organizational learning}

Organizational learning is a mechanism an organization disposes of, in order to get adapted to its external environment. In fact, there are two kinds (Argyris \& Schön, 1996): singleloop and double-loop learning.

Single-loop learning refers to making things in a better way. On the contrary, double-loop learning refers to making new things, and not just making the same old things better. 
It is clear that single-loop learning might not be sufficient for an organization to get adapted to its external environment. Imagine a change in the surrounding environment of an organization, for example, regarding customers' needs. In this case, improving the manufacturing processes will not lead to a better result in terms of profitability, as making manufacturing processes faster will not lead to the new products that address the needs the customers are requesting.

In this case, it would be necessary to replace the old manufacturing processes with new ones. In fact, a new specification should be derived from the identified needs of the customers, as a result of a systems architecting effort. Then, the manufacturing processes leading to the final product should change to get adapted to that new product specification.

This can only be addressed by means of a double-loop learning process. This means that the organization manufacturing the products needs to change the way its internal processes are performed in order to provide its customers with a different output. In order to achieve this aim, the organization must have first inspected its surrounding environment.

Then the organization has to inspect its inside processes. Once this task is performed, it is possible for the organization to know how it has to modify its internal processes so that it can respond to the demands of its external environment.

This adaptation of the organization to its external environment is in fact double-loop learning, for the organization questions itself regarding the way it is performing within its environment. As the demands of its environment change, the organization modifies its internal behavior in order to survive and prosper.

This behavior is very similar to what can be found in biological organisms like an ameba or a human being. The theory of evolution clearly states that only the most adaptable organisms survive. In fact, the meaning of the term "adaptable" is heavily related to the rapidness with which adaptation takes place.

The rapidness of double-loop organizational learning is an unclearly understood phenomenon, mainly regarding its causes. It is clear that there should be some triggering effects that should foster it, but which are these effects is pending to be researched.

The way an organization translates its needs into processes is described by Crawley (2011). Figure 3 shows how a beneficiary's need is first translated into a transforming process, which in turn is carried out by means of a specific system's operating concept.

Therefore, it is clear that if changes occur within the outside environment of an organization, the corresponding process inside that organization has to change leading to fulfill the new identified need. In the instance above, the transforming process would change in order to address the new need. 


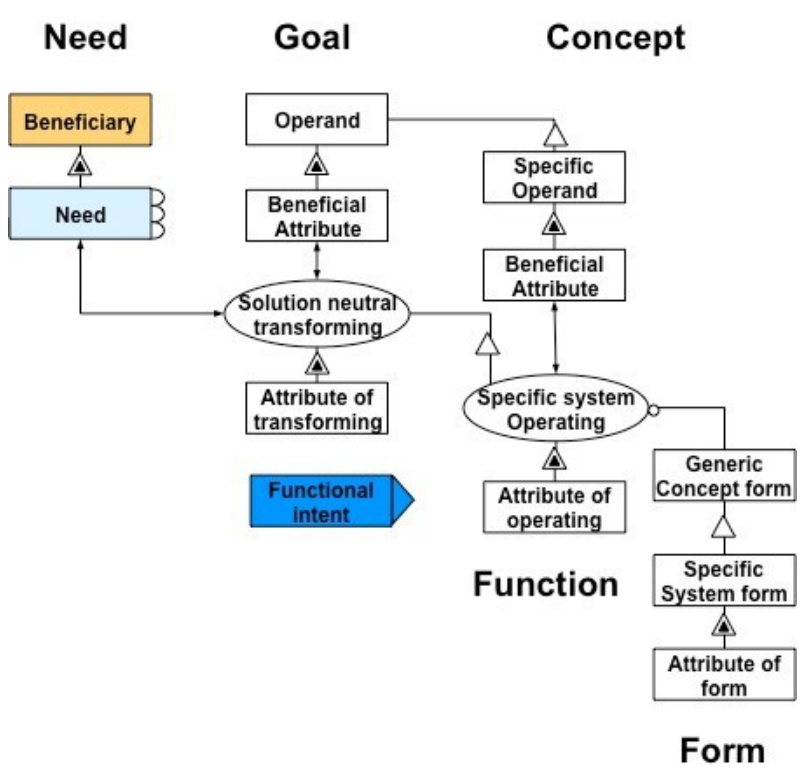

Figure 3. Framework for needs to concept (Crawley, 2011)

One of the issues that an organization has to manage when dealing with double- loop learning is the concept of conflict. This is described by March and Simon (1993), and it refers to the level of disagreement among either the individual members of a given organization or organizational units, which can have a different perception on a certain matter.

The importance of conflict is that it is a force that operates oppositely to the cohesive efforts of an integrative force leading to the transformation of the internal processes of the organization.

\section{System characteristics}

The information systems characteristics needed for gathering and processing of data useful for decision taking, regarding the adaptation of an organization to its environment can be divided into two interfaces: the one of the organizational information systems with their external environment and the other of the organizational information systems with the organization itself. This is depicted in Figure 4.

On the one hand, information systems retrieve information from the outside in order to manage to get a picture from its external environment. On the other hand, information systems retrieve information from the organization in order to get a picture from its internal manufacturing processes.

The information systems interface with the organization has an additional internal interface. Once the information systems retrieve information from the inside and the outside, it is time for them to generate decisions regarding the planning of the internal processes so that they generate the output demanded by the organization's external environment. 


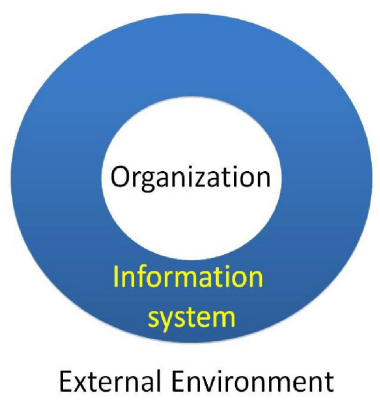

Figure 4. Information systems interfaces

The structure of the internal decision support system needed for the taking of a decision regarding the planning of the internal processes based on internal and external information is depicted in Figure 5.

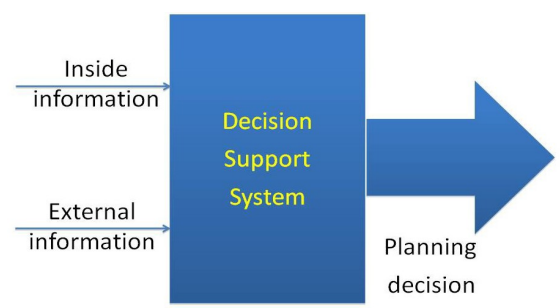

Figure 5. Decision support system internal structure

The balanced scorecard methodology can be used to detect the main organizational processes and the modifications to be carried out within them (Kaplan \& Norton, 1996). It starts with analyzing the organization's mission and vision in order to identify the main strategic goals, which must be quantified as financial objectives.

To reach those financial objectives, an organizational analysis from the customer's point of view must be carried out. Once this has been done, the main processes directly affected will be identified and subsequently reviewed.

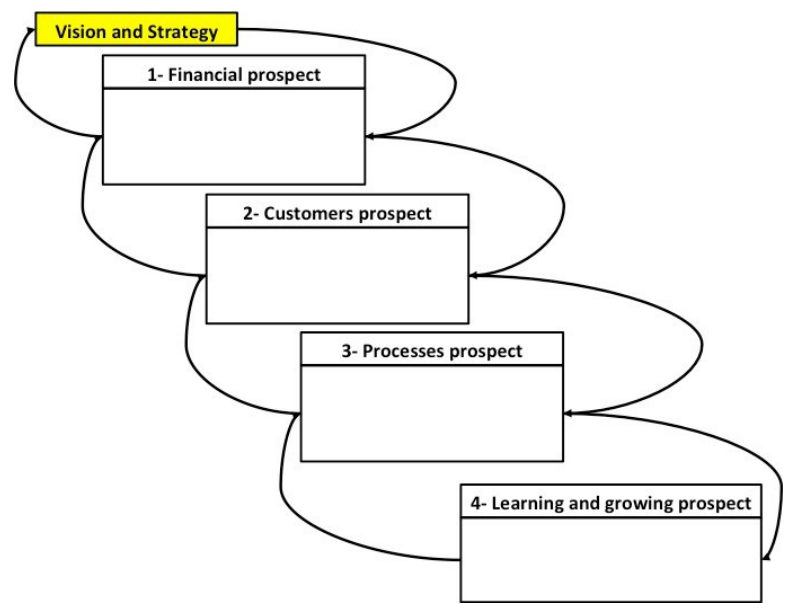

Figure 6. Balanced scorecard (Kaplan \& Norton, 1996) 
The ultimate step is to communicate to the personnel this way of acting in order to achieve their cooperation in identifying the customer's wishes, information that may be tacitly registered in their brains to explicit it on either new processes to be developed or by adapting processes in force. The whole methodology can be seen depicted in Figure 6.

It is also possible that as part of the planning decision, information systems themselves have to be modified, especially when it is decided that organizational change be managed through their transformation (Scott-Morton, 1991).

\section{Conclusions}

It has been discussed how the use of information systems can be leveraged to make organizations adaptable to their external environment. The basic features of these decision support systems include one input with information from the inside and another one from the outside of the organization. The output might modify the way internal processes are carried out, including a possible reorganization of the organizational information systems to help drive this change. This paper just sets a framework for the development of a future set of studies in organizational learning supported by information technologies.

\section{References}

Argyris C., \& Schön D.A. (2005). Organizational Learning II: Theory, Method, and Practice. United States of America: Addison-Wesley.

Crawley, E. (2011). System Architecture: September 9. Cambridge: Massachusetts Institute of Technology.

Kaplan, R.S., \& Norton, D.P. (1996). The balanced scorecard: translated strategy into action. Boston: Harvard University Press.

Laudon, K.C., \& Laudon, J.P. (2009). Management Information Systems: Managing the Digital Firm. Harlow: Pearson.

March, J., \& Simon, H. (1993). Organizations. Cambridge: Blackwell Business Publishers.

Scott-Morton, M. (1991). The Corporation of the 1990s: information technology and organizational transformation. New York: Oxford University Press.

Journal of Industrial Engineering and Management, 2013 (www.jiem.org)

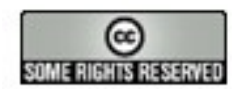

Article's contents are provided on a Attribution-Non Commercial 3.0 Creative commons license. Readers are allowed to copy, distribute and communicate article's contents, provided the author's and Journal of Industrial Engineering and Management's names are included. It must not be used for commercial purposes. To see the complete license contents, please visit http://creativecommons.org/licenses/by-nc/3.0/. 